\title{
Sizing Up the Fermi Surface: Brian Pippard Speaks of Metals, Methods, and Songs
}

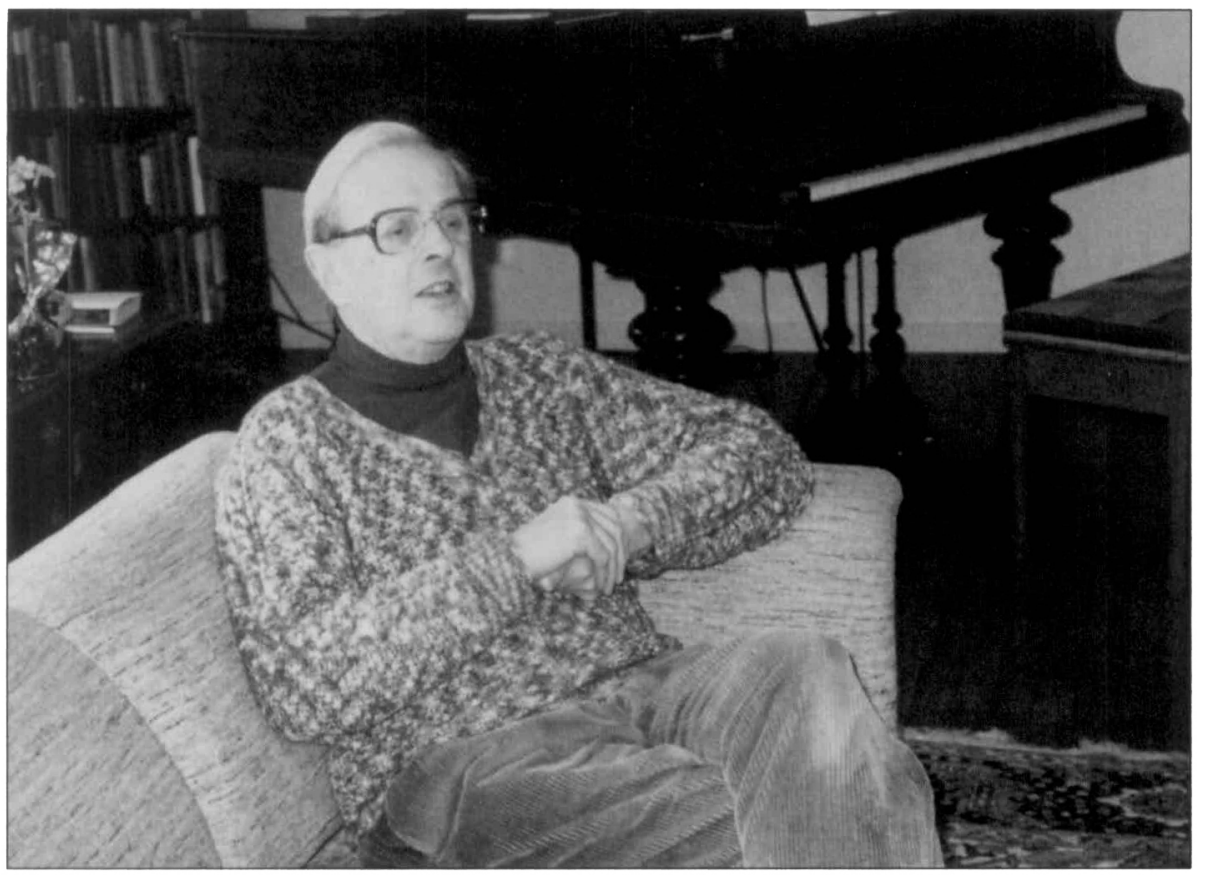

Sir Brian Pippard, a most distinguished British physicist whose career has been devoted to the Cavendish Laboratory at Cambridge University, agreed to meet with MRS Bulletin at his home in Cambridge last fall. Sir Brian is a man who follows his instincts without letting convention interrupt his path. Research grants were virtually unknown mid-century, so out of necessity he built his own research equipment to pursue his work. Later, he put his efforts toward educational reform in Cambridge, hitting a wall of indifference.

While our agenda was to discuss physics and Sir Brian's contributions to materials science, the surroundings reminded us that his scientific contributions are balanced by a love of music. A piano sat beside us, and a music stand served as a place to drape the microphone to capture his words. Once, this engineering construct failed, causing the microphone and stand to tumble from the coffee table to the floor, reminding us that every path has side trails and pitfalls, but one does not dwell there for long.

Sir Brian would rebut any suggestion that he be termed a materials scientist, but his experiences carry lessons for us nonetheless. In 1956, he spent a period as a visiting professor at the Institute for the Study of Metals in Chicago and there he performed one of the key postwar experiments in solid-state physics, the determination of the shape of the Fermi surface in copper. He used as a tool the anom- alous skin effect at microwave frequencies, which is linked to the Fermi energy in different crystal directions. We asked him to tell us something about that year.

Would you say, Brian, that your time in Chicago was really an application of metallurgical skills to the physical problem that you had set for yourself on why skin-effect measurements exposed geometrical results?

That is exactly right. I had realized the year before, 1954 I think, that by doing measurements of the high-frequency skin effect on very pure metals with clean surfaces, one could get geometrical informa-

\footnotetext{
*The anomalous skin effect method involves applying a high-frequency field to a very pure single crystal of metal at very low temperatures. The field induces currents in the metal, which tend to prevent penetration of the field into the specimen, limiting it to a certain "skin depth." At these low temperatures, the electron mean free path is much longer than the skin depth and only those electrons that run nearly parallel to the surface and within the skin depth remain in the field long enough to receive appreciable energy from the field. The effective resistance under these conditions is a function of the radius of curvature of the Fermi surface at those points that refer to electrons moving parallel to the surface; the anisotropy of the resistance for different crystallographic orientations can be used to test assumed models of the Fermi surface and to determine its shape.
}

tion about the dynamics of the electrons in the metals. The shape of the Fermi surface was not known in any metal at that time, but it had been conjectured and various calculations had been done. Then, I was absolutely delighted to find-when I did the calculations of the method-that the high-frequency resistance at the surface could be used as a way to gather straightforward geometrical information about the surface. However, the skin effect only goes down to about $10^{-4} \mathrm{~cm}$ and the surface of a material can easily be damaged by cutting and polishing. So, one needed to study single crystals of, say, copper cut into thin plates (1 or $2 \mathrm{~mm}$ thick and about an inch in diameter) and one needed them to have very high purity and very smooth, clean, strain-free surfaces.

I did not know how to proceed, but Morrel Cohen of the Institute for the Study of Metals from Chicago was passing through Cambridge and I told him about this possibility. He was a very young staff member in Chicago in those days. I can't remember whether I had the distinct intention that he should invite me to go to Chicago but he thought I did and invited me to go where they had the techniques to do this. The Institute was very good about ! it. Before I arrived they had grown a very large single crystal of pure copper. It was about $11 / 4$ in. in diameter and 6 in. long. They started chopping the sample and their expert polisher went to work polishing it. When I arrived, the lab was set up, which is jolly good if you only have a year. I suggested how they should do the cutting. It was a question of getting the right set of orientations out of the given crystal. They had diamond saws and that sort of thing. They did it very nicely, indeed.

As it happened, I already had the appropriate apparatus for doing the measurements built in Cambridge and brought it with me. I had no sooner begun working with the new specimens, however, when I found that the apparatus was not working well. I scrapped it and got a new design built in the workshop of Chicago, which took about three months. During those three months, I took the opportunity to write my book on thermodynamics, which I had been lecturing on at the undergraduate level for some years.

The new apparatus was extremely good. The design I had chosen was for measuring the heat developed when centimeterwavelength radiation fell on the specimen. I intended to do the measurements by 
using a resistance thermometer. What I didn't realize was that the resistance thermometer would be very badly affected by the tiniest stray microwave field.

\section{Didn't you also use a gas thermometer?}

I started with the resistance thermometer, then switched to gas thermometers.

\section{Going back to the 19th century?}

Exactly, yes. And they worked very nicely, too.

It must have been an unusual experience for you to do your research by yourself. Other people prepared the samples, right, but you did all the measurements and so forth. Whereas, when you returned to the Cavendish, you had the usual gaggle of research students?

Yes, but in those happy days, each of the research students did his own thing. We were all solo workers. In the days before I went to Chicago, from ' 45 to ' 55 , the only help I had from research students was when they helped by controlling the temperature and taking down readings.

The special thing about Chicago was working underground under the [baseball] stands. Some of the low-temperature work was conducted in a sort of basement area, which was fine most of the year, but when the summer came on and the temperature went to about $90^{\circ} \mathrm{F}$ and the humidity to about $90 \%$, it was extremely unpleasant working there. The only thing that comforted me about being in those appalling conditions was that I, at least, was a public school boy and I was taught to withstand hardship without complaint, whereas my colleagues were Americans and had not been taught not to complain. I was smiling bravely in spite of the heat.

How did the samples survive the conditions?

The samples survived very well. There was one moment when I couldn't take a resistance measurement because water was streaming down the equipment. Condensation, you know. But otherwise it went very well, indeed.

How did your work in Chicago fit in with the science of fermion research at the Cavendish? And why did you choose copper?

The story is roughly this: As you know David Shoenberg, before the [Second World] War, had done some very good measurements on the deHaas-van Alphen ${ }^{\dagger}$

tThe deHaas-van Alphen effect results when a strong magnetic field is applied to a single crystal of a metal at very low temperatures. The magnetic susceptibility oscillates periodically with the inverse of the magnetic field, and information about the shape and size of the Fermi surface can be derived from the period of this oscillation. effect in bismuth. This effect had only been found in bismuth. He put that aside and turned to superconductivity. Shortly after the [Second World] War, Jules Marcus at Northwestern found the effect in cadmium, which caused renewed interest. David, around 1950, began doing more measurements on the deHaas-van Alphen effect. At the same time, Lars Onsager from Norway was spending a year in Cambridge, studying the deHaas-van Alphen effect. His short paper published in 1952 in Philosophical Magazine laid the foundation for interpreting the deHaas-van Alphen effect in terms of the geometry of the Fermi surface.

For the next two years or so, nobody took his findings very seriously. When I found that the skin-effect measurements would give geometrical results, it certainly occurred to me: What if this is something of what Onsager is saying about geometry of Fermi surfaces? So, I went back to look at his paper and found, my goodness, he's got something much more powerful. I think that David Shoenberg probably had realized this himself, but certainly when I pointed this out to him, it strengthened his motivation to make a serious attack on the deHaas-van Alphen effect as a means of determining Fermi surfaces.

That takes us to 1954. "Why copper?" you say. Well, because copper is an important metal! It was simple enough and one that was taken seriously. I had a research student, Eric Fawcett, who was working on similar effects in tin. This was before I got the theory. He was just looking to see what happened. Tin, however, was much too messy.

Meanwhile, David Shoenberg had been working on his deHaas-van Alphen effect and had to wait until ' 56 or ' 57 before he had the apparatus for working with really strong impulsive fields. Then he tried copper but could not reproduce my results for the Fermi surface by his technique. Where little orbits around the neck would have given very noticeable oscillations of the effect, he found nothing. He was working on a very beautiful, tiny whisker of copper that had been sent to him by an American friend who was working on whiskers. $\mathrm{He}$ in his innocence believed his friend's statement about the crystal orientation of this whisker, but it was wrong. It was not surprising that he failed to find the effect. In fact, around 1957, I went to a conference in Oxford where I presented my results and showed a picture of the Fermi surface of copper that I determined. Just before that, I

Profiles \& Perspectives explores the people behind the profession of materials research.

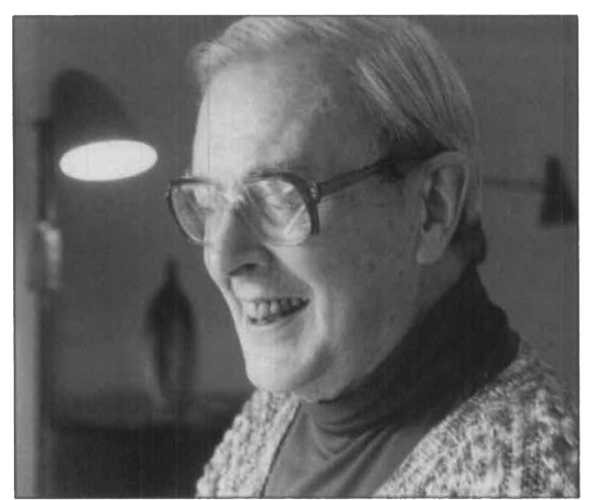

received a telegram from David to say that the contact with the zone boundary does not exist. He said it doesn't show up in the deHaas-van Alphen effect. I remarked in my talk that I had this telegram, and indeed I hadn't found contacts directly, but had inferred them from the fact that my Fermi surface wouldn't fit into the Brillouin zone, which meant that the Fermi surface did cut the Brillouin zone. My method was simply not sensitive enough to get the shape at this critical point. Once the crystallography was worked out, everything went beautifully.

Your Fermi surface experiment depended on the anomalous skin effect.

I have been laughed at in a friendly way for calling it the anomalous skin effect. The reason I called it that is because Heinz London in his 1940 paper said he had noticed certain anomalous features in the skin effect.

During your superconducting work before you ever did the Fermi experiment, you apparently set out with certain objectives, found something unexpected that tickled your imagination, and apparently without hesitation dropped your original objective and moved onto a new one. Have you done that often and do you think that it is an important thing to do in scientific research?

I was trying to understand how the high-frequency resistance of a superconductor was affected by the behavior of the normal electrons and, therefore, I expected that adding impurities would change the conductivity of the normal electrons. That was the thrust of my study. Well, as soon as I found evidence that the penetration depth was changing, it was obvious that this was a much more significant fundamental result. I dropped the original study, which was boring and not obviously productive, and started looking into this new result.

Of course, if you're working on a specific financial grant you may not be free to make that change.

That didn't arise at all. There were no 
financial grants. In those days I made almost all of the apparatus myself. One of the workshop men made $3-\mathrm{cm}$ waveguides for me out of thin German silver sheet. Otherwise, I think I made everything myself. There was no money involved.

What people don't realize is that the present awful state of finance in science is absolute luxury compared to what it was in the ' 30 s and ' 40 s. If you could make your apparatus, you did. If you couldn't, you cannibalized someone else's. Chicago was generous enough to make me a visiting professor and pay me, and Cambridge, having ascertained I had enough money to live on, granted me a sabbatical leave without pay.

The first research grant I had was about 1960 when I built a high-field magnet in the Cavendish. I think I received $£ 50,000$, which was a lot in those days.

In your Philosophical Transactions paper in 1957, you said that you cast aside physical ideas as far as you could because they were inclined to obscure your search for a solution. How easily would you say the mind is tricked into anticipating a certain answer? What was in your mind when you wrote that statement?

I was well aware then as I am now that my grasp of theoretical subtleties is not very good. Therefore, it was a great mistake to be too confident of one's own understanding. It was better to take things as they come from the experiment. On the general point, I think that a preconceived notion can be extremely harmful. If you're looking for an explanation for a phenomenon, a preconceived notion may prevent you from ever thinking of the right answer. If you happen to hit on the right answer, you're less likely to reject it. However, the real danger of preconceived notions is it stops you from thinking along the right lines if they don't mesh with your original idea. A reasonably honest scientist can say, "Well I didn't expect this, but it does seem to have something in it." There are many not so reasonably honest people who would say it can't possibly be true if it goes against their notions.

One of the last books you wrote, in the early 1990s, was concerned with magnetoresistance. How did you get involved in this field?

When I began work in this field, there was no adequate theory of magnetoresistance. In our experiments, my research students and I were trying to understand the magnitude of magnetoresistance in ordinary metals and why it is so extraordinarily dependent on crystal orientation. We worked with pure single crystals of simple metals like copper.
Did you envision that there would be practical uses later?

I knew that there would be practical uses in the sense that some Russian scientists had used the magnetoresistance in bismuth to plot out the magnetic field in mixed superconducting states. However, I had no idea that magnetoresistance would be used in recording because the ferrite business was going so well.

This has been a strain on the English language. We began with magnetoresistance, moved to giant magnetoresistance, and then to colossal magnetoresistance.

And colossal magnetoresistance is absolutely minute compared to the magnetoresistance I was interested in. The sort of thing you get in reasonably pure, singlecrystal metals increases resistance by a factor of thousands or many thousands-and in bismuth, millions. That is what I call good magnetoresistance. Whereas, the giant magnetoresistance is worth $10 \%$ or something of that sort.

"The real danger of
preconceived notions is it
stops you from thinking
along the right lines if they
don't mesh with your
original idea."

In the past decades, physics and metallurgy have undoubtedly grown closer together. Can you describe to what degree this has happened in Cambridge and is it true that you and Sir Alan Cottrell at one stage actually hatched a plot to merge the two disciplines in Cambridge?

I remember as Alan and I were traveling back from London on the train we talked about the desirability of a closer connection between metallurgy and physics. I can't speak for his conclusions, but I was certainly encouraged to believe that in the long run the two departments could well combine under a common head of department. I had a private ambition that the next professor of metallurgy in the University should be a physicist who was interested in metallurgy. I didn't want to take over metallurgy for other purposes. It is quite clear that when rumors of this idea reached metallurgists-the more metallurgical metallurgists-they felt it was an obvious attempt to take over their department. They would resist at all costs. When it was necessary to replace Wesley Austin [head of the Metallurgy Department], the committee ruled the person must have his interests centered on metallurgy. I was on the General Board of the Faculties at the time when this ruling was made and all the arts people on the Board asked in puzzlement: What does this mean when they ask that the professor of metallurgy must be a metallurgist? They didn't know the inside information of what was going on.

How did you become involved in improving undergraduate and graduate education in Cambridge, not only in physics but in other fields as well?

My involvement came from serving on the Swann committee on science and industry in the late ' 60 s. The Swann committee was one of the ongoing government committees on the training of scientists for the country's needs. While an earlier committee of the Physical Society was discussing the question of training a supply of scientists for industry, it occurred to us that it would be a good idea to find out how many British scientists were in the United States. So we published a list-I think we listed 20 section leaders at Bell Labs who were British-trained at that time.

We had a lot of discussion on the Swann committee about whether a general training in science might be better than a specialized one. In the ' 50 s and ' 60 s we worked under the notion that a general science education would be a very good course. The only trouble, we discovered, was that nobody actually wanted to employ such graduates. I developed a $2+2$ scheme in which universities, including Cambridge, would offer a four-year course for the most committed undergraduates and a two-year course for the less committed. The people who didn't want a professional education, I thought, ought to have a general education. We needed four years of education for a solid professional training but could not get four years without sacrificing something. The government would say three years is the right amount. So, to have half the students doing two years and half doing four would provide what the government required and also what was required academically to get professional training. But it isn't making any serious headway.

\section{Why did you run into problems?}

Because it was a new scheme.

"Nothing must ever be done for the first time," as someone said a century ago?

Especially in academia. Academics will not accept anything suggested by someone else. They want it to be their idea. We are trained that way.

In the foreword of Michael de Podesta's book, Understanding the Properties of Matter, 
you wrote, "Once [the lesson of this book] has been learnt, it will remain a source of information and, more important still, an incentive to continue with the process of self-education which is the key to achievement." Would you say that Cambridge University prepares students for self-education?

It is what traditionally we believe matters, yes. This is particularly true, I think, of the tutorial system or small-group teaching. It is also true that good lecturers should be encouraging their students to get excited. The conventionally "good" lecturers who give the students information they can reproduce in the exam are not doing their jobs. It is the conventionally "bad" lecturer who goes off on a tangent and successfully excites those students who will take to being excited.

It doesn't matter what they do to the rest of the stude its?

Well, tha is where the tutorial system comes in and makes good a lecturer's deficiencies. Of course, ideally a lecture should not only be absolutely clear, but also inspiring. It is very hard to reach that ideal.

What should the students do with that inspiration to make sure that they can be successful in science?

If a lecturer is successful in inspiring students, it means that the students will start thinking for themselves. You will not see any immediate improvement in a specific way, but their lives will be changed. You notice this in the tutorial work occasionally. Very rarely, I have noticed it. For instance, if a student has come along with a problem and I have tried to solve the problem, but got bogged down with it, the student then sees me work through the problem. "This is no way of doing it. Let's try this way," I say as I begin again. Then, I have noticed that once or twice in the whole of my teaching career, when I have reached the end of a problem and have suddenly and triumphantly found the answer, I've looked at a student and seen that he is quite riveted by the fact that he has seen someone thinking.

You should never be ashamed of getting caught in a mess in a lecture provided that you get yourself out of the mess publicly. In fact, I ran across this in the last few years when I was teaching an optional course for third-year students on experimental method. I would set a problem for the class to discuss. The important thing was not to know the answer beforehand. To stand up in front of a class and be prepared to make mistakes publicly and have the students say, "that wouldn't do sir, because ...." I found that if the students were encouraged to do that, they would then speak themselves and they wouldn't mind if another student said, "Oh what nonsense you are talking," because they would always have a chance when the next student tried his solution to be beastly to him in turn. The result was that everyone was actually nice to everybody. They would say "nonsense" in the friendliest possible way. I thought that was successful teaching. I enjoyed that enormously.

Are you saying that once scientists have established themselves in the field, they ought not to be afraid of making occasional mistakes?

I would distinguish between a sensible mistake and a silly mistake. One always ought to be ashamed of making a silly mistake. On the other hand, a sensible mistake would show you and your listener that there is a puzzle here and that no person understands it. It is worth thinking about. Those are sensible mistakes. Jean Lamarck made a sensible mistake about evolution [which suggested that evolution was based on inheritance of acquired characteristics].

Do you think there is a danger that when students see the right way and the wrong way, they won't be able to remember which way is right?

Of course, there is a danger, but a lecturer having got things clear should explain why the wrong answer is wrong. It is very easy to gloss over one's faults.

"It is a great thing for
lecturers to get into a hole and
dig themselves out publicly
when they are young, because
from then onward they will
have confidence and can afford
to take chances."

The crucial thing-and this is where most lecturers are at fault-is that they lack confidence. It is a great thing for lecturers to get into a hole and dig themselves out publicly when they are young, because from then onward they will have confidence and can afford to take chances.

Besides being a scientist, how do your other interests advance or in some subtle way have a role to play in your profession?

It is quite reasonable to say that music is central to my life. I hardly go for any time

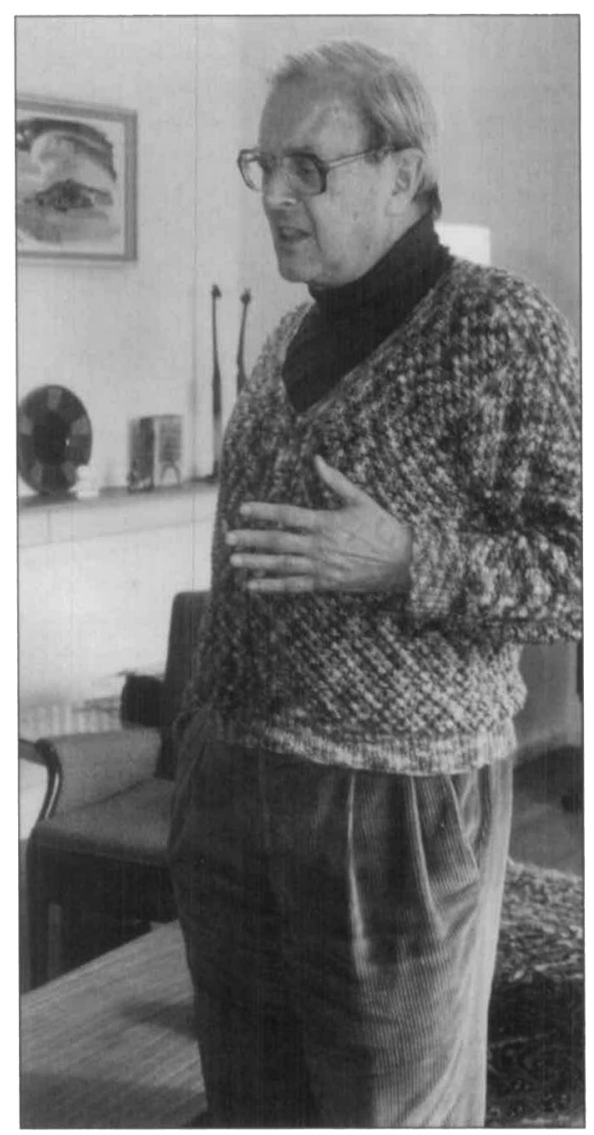

without music running through my mind. It doesn't have to be great music. I don't always think about Rostropovich. Even if it is only just jingles, music is there.

Do you play musical instruments or do you listen to recordings?

I have a few recordings but I rarely play them. I listen to the radio. I try to get to my piano every day and I have a number of friends who play chamber music together. I keep active there.

Does science play in your head too or can that be turned on and off?

It used to, but now my mind has stopped seriously working on research issues. Research, I'm afraid, is impossible any more.

While his own scientific endeavors take their place in history, it is easy to see the joy Sir Brian took in the research he did with his own hands and in imparting his way of thinking to the students he guided. As the next generation of scientists under his inspiration carry on with open minds, Sir Brian steps back and listens to the music.

The interviewers were

MRS Bulletin Editor Betsy Fleischer and Editorial Board Member Robert W. Cahn 